\title{
A Study on the Efficacy of Immunotherapy with Purified Protein Derivative for the Treatment of Recalcitrant Warts
}

\section{Neerja P}

Consultant Dermatologist, Punjab Health systems Corporation.

\author{
Address for correspondence \\ Dr. Neerja Puri \\ House No 626, Phase li, Urban Estate \\ Dugri Road, Ludhiana. Punjab (India) \\ Cell : 0091-98146-16427 \\ E-mail: neerjaashu @ rediffmail.com
}

\begin{abstract}
Introduction: There are many treatment modalities of warts, but most of them are destructive therapies which have propensity to cause scarring. Many antigens especially purified protein derivative (PPD) of tuberculin bacilli are being used for the regression of warts.

Objective: To study the efficacy of purified protein derivative of tuberculin bacilli in the treatment of warts.

Material and Methods: A randomized controlled trial was done in which 25 patients of recalcitrant warts were taken up for the study. In all the patients, 2.5 units of PPD was injected in each wart and upto maximum of 25 units PPD was given and the injections were given every 3 weeks for a total of 3 sessions.

Results: Commonest type of wart seen in our study was verruca vulgaris in $15(60 \%)$ patients, verruca plana in $5(20 \%)$ patients, palmoplantar warts in $3(12 \%)$ patients and genital warts in 2 (8\%) patients. Regarding the number of warts 15 (60\%) patients had more than 20 warts, $5(20 \%)$ patients had number of lesions between $11-20$ and another 5(20\%) patients had lesions between $1-10$. Complete clearance of lesions after 3 sessions was seen in $18(72 \%)$ patients, partial clearance of lesions was seen in $4(16 \%)$ patients and no response was seen in $3(12 \%)$ patients.

Conclusion: Immunotherapy with PPD causes boosting up of the cell mediated immunity of the patients which causes spontaneous regression of the warts.
\end{abstract}

Key words: immunotherapy; purified protein derivative; regression; cell mediated immunity.

\section{Introduction}

P urified protein derivative of tuberculin bacilli has been used to boost cell mediated immunity in patient with warts. ${ }^{1}$ The course of warts is quite variable in various individuals. In some patients, warts regress spontaneously by themselves within a period of few months to few years. This is due to the cell mediated immunity of the person, which helps in spontaneous regression of warts. ${ }^{2,3}$ There are various modalities for the treatment of warts including various physical and chemical modalities. But the main problem with most of the destructive modalities is the high incidence of scarring with their use. The main advantage of immunotherapy is the lower rate of recurrence of warts and also less chance of scarring. There are various antigens used for immunotherapy including candida antigen, mumps antigen and trichophytin antigen. $^{4,5}$

\section{Objective}

To study the efficacy of purified protein derivative of tuberculin bacili in the treatment of warts.

\section{Material and Methods}

A randomized controlled trial was done in a district hospital in North India in which 25 patients of recalcitrant warts were included in the study. In all the patients, 2.5 units of PPD was injected in each wart and upto maximum of 25 units PPD was given. The injections were given every 3 weeks for a total of 3 sessions. Adrenaline was kept ready in the emergency 
tray for any untoward anaphylactic or hypersensitivity reactions. Clinical response was assessed by physician global assessment score and also by photographic record which was done at every visit.

\section{Inclusion Criteria}

The following patients were included in our study:

- Patients with recalcitrant warts

- Patients having extensive warts

- Patients who have taken no treatment for the past 3 months

\section{Exclusion Criteria}

The following patients were excluded from our study:

- $\quad$ Pregnant and lactating females

- Patients on immunosuppressive drugs

- Patients having active tuberculosis and on anti tubercular drugs

- Patients having any severe allergic reaction to tuberculin PPD

The response to treatment was graded as follows:

Complete clearance $-75-100 \%$ response

Partial Clearance - $50-74 \%$ response

No Clearance $-<25 \%$ response

Follow up of the patients was done for a period of 6 months.
Written informed consent was taken from all the patients before the study.

Prior permission of hospital ethical committee was taken for the study.

\section{Results}

The data was collected, tabulated and the results were analyzed statistically using chi square test.

\section{Results}

There were 15 males and 10 females and male: female ratio was 1.5:1. Maximum number (56\%) of patients were between $21-40$ years of age followed by $8(32 \%)$ patients between $0-20$ years of age and $3(12 \%)$ patients were between $41-60$ years of age. Commonest type of wart seen in our study was verruca vulgari in 15 (60\%) patients, verruca plana in 5 (20\%) patients, palmoplantar warts in $3(12 \%)$ patients and genital warts in 2 (8\%) patients. Regarding the number of warts, 15 (60\%) patients had more than 20 warts, 5 (20\%) patients had number of lesions between $11-20$ and another 5 (20\%) patients had lesions between $1-$ 10. Complete clearance of lesions after 3 sessions was seen in 18 (72\%) patients, partial clearance of lesions was seen in $4(16 \%)$ patients and no response was seen in $3(12 \%)$ patients.

Table 1 : Age wise distribution of patients

\begin{tabular}{|c|c|c|c|}
\hline S. No & Age Distribution (Years) & Number & Percentage \\
\hline 1 & $0-20$ & 8 & $32 \%$ \\
\hline 2 & $21-40$ & 14 & $56 \%$ \\
\hline 3 & $41-60$ & 3 & $12 \%$ \\
\hline 4 & $>60$ & - & - \\
\hline
\end{tabular}

Table 2: Type of Warts

\begin{tabular}{|c|c|c|c|}
\hline S. No & Types Of Warts & Number & Percentage \\
\hline 1 & Verruca vulgaris & 15 & $60 \%$ \\
\hline 2 & Verruca plana & 5 & $20 \%$ \\
\hline 3 & Palmoplantar warts & 3 & $12 \%$ \\
\hline 4 & Genital warts & 2 & $8 \%$ \\
\hline
\end{tabular}

Table 3: Number of Lesions

\begin{tabular}{|c|c|c|c|}
\hline S. No & Number Of Lesions & Number & Percentage \\
\hline 1 & $1-10$ & 5 & $20 \%$ \\
\hline 2 & $11-20$ & 5 & $20 \%$ \\
\hline 3 & $>20$ & 15 & $60 \%$ \\
\hline
\end{tabular}


Neerja $P$

Table 4: Response to Treatment

\begin{tabular}{|c|c|c|c|}
\hline S. No & Response to Treatment & Number & Percentage \\
\hline 1 & Complete clearance & 18 & $72 \%$ \\
\hline 2 & Partial clearance & 4 & $16 \%$ \\
\hline 3 & No response & 3 & $12 \%$ \\
\hline
\end{tabular}

Table 5: Side Effects Of Treatment

\begin{tabular}{|c|c|c|c|}
\hline S. No & Side Effects & Number & Percentage \\
\hline 1 & Erythema & 5 & $20 \%$ \\
\hline 2 & Oedema & 2 & $8 \%$ \\
\hline 3 & Pain & 1 & $4 \%$ \\
\hline 4 & Recurrence & 2 & $8 \%$ \\
\hline 5 & Fever & 1 & $4 \%$ \\
\hline
\end{tabular}
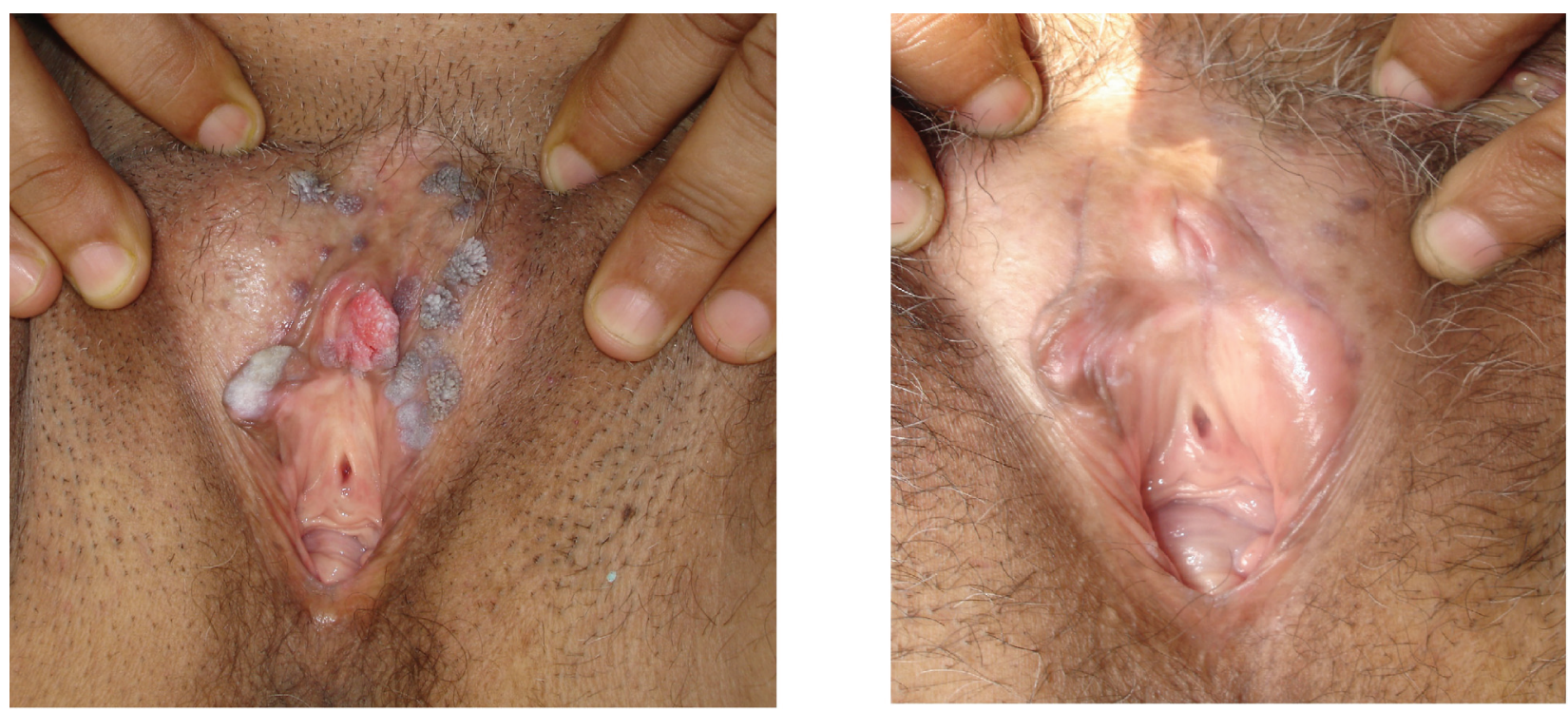

Fig 1: Pre and Post Treatment Photograph of 45 years old female patient of Genital Warts

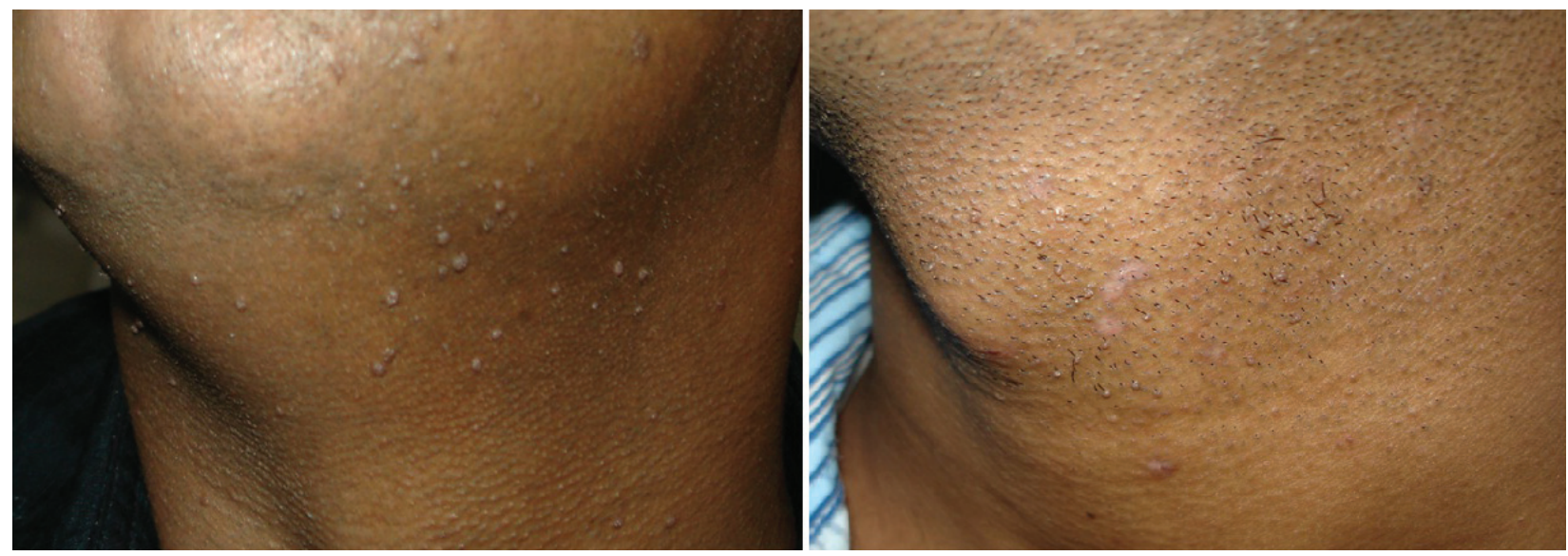

Fig 2: Pre and Post Treatment Photograph of 25 years old male patient of Verruca Plana 
The side effects of injection PPD seen were erythema in $5(20 \%)$ patients, edema and recurrence after treatment in 2 (8\%) patients each, pain and fever in 1 (4\%) patients each. Oedema and redness responded to cold compresses. Recurrence was seen in 2 patients during the follow up period. In most of the patients in whom immunotherapy was given, no scarring was observed in any of the patients and also recurrence was very less as compared to the other modalities.

\section{Discussion}

Tuberculin purified protein derivative is presently used for detection of infection by mycobacterium tubercules. ${ }^{6}$ The first preparation of tuberculin was prepared by Robert Koch in 1890 , by heat killing the culture of tubercle bacilli at $100^{\circ} \mathrm{C}$. In 1941 , PPD was a purified product. In India, tuberculin PPD is available as diluted and ready to use solutions in $1 \mathrm{ml}, 2 \mathrm{ml}, 5 \mathrm{ml}$ and $10 \mathrm{ml}$ vials. Intradermal injection of PPD results in stimulation of sensitized $T$ cells and results in delayed hypersensitivity reaction, which begins at $5-6$ hours and becomes maximum at 48-72 hours after the administration of tuberculin PPD. Since PPD is a biological product, adrenaline should be available to treat anaphylactic or acute hypersensitivity reaction, though such reactions are extremely rare after administering tuberculin PPD. ${ }^{7}$ All the routine modalities have a tendency to cause depigmentation and scarring and frequent recurrences can occur. Regression of warts can occur spontaneously due to the development of cell mediated immunity. It is important that the PPD injection should be used with caution in patients on beta blockers as they may become unresponsive to adrenaline if anaphylactic reaction occurs.

In our study, complete clearance of lesions after 3 sessions was seen in 18 (72\%) patients, partial clearance of lesions was seen in $4(16 \%)$ patients and no response was seen in 3 (12\%) patients. The result of the our study was comparable to a study by S. Wananukul et al, in which $67 \%$ cure rate was seen as compared to $72 \%$ in our study. ${ }^{10}$ In another study by Ibraheem, there was complete cure in 32 cases (94.1\%), which is much more as compared to our study. ${ }^{9}$

In a study by Easaa et al, a total of 40 pregnant women, aged 20-35 years with anogenital warts were enrolled. The patients were treated with weekly injections of PPD given intradermally in the forearms, and evaluated for the response regularly. ${ }^{8}$ Nineteen (47.5\%) patients demonstrated complete clearance, 15 (37.5\%) had partial response, and three $(7.5 \%)$ had minimal response. Three $(7.5 \%)$ cases did not respond to treatment. Side effects were minimal and insignificant. Treatment of anogenital warts in pregnant women with intradermal injection of PPD was found to be a unique, safe, and effective modality of immunotherapy.

Ibraheem evaluated the effect of intradermal and intralesional Purified Protein Derivatives (PPD) in treatment of warts. ${ }^{9}$ One hundred and ten patients with warts were included and classified into 3 groups: first group included 40 patients treated with intralesional PPD, second group included 50 patients treated with intradermal PPD \& the third group included 20 patients as a control group treated with intralesional saline with a dose of $0.1 \mathrm{ml}$. The response to PPD was complete cure in 32 cases ( $94.1 \%$ ) in the first group,48 cases $96 \%$ in the second group.

In another study by S.Wananukul et al, tuberculin PPD injected intralesionally to the largest wart resulted in $67 \%$ cure rate with three treatments. ${ }^{10}$

Intralesional immunotherapy with PPD is used to induce a delayed hypersensitivity response to various antigens and the wart tissue. ${ }^{11,12}$ It is associated with production of Th1 cytokines which activate cytotoxic and natural killer cells to eradicate HPV infection. This helps to clear both local and distant warts. PPD injection stimulates the local immunity and also causes circulation of activated T cells in the body and ultimately causes clearance of both injected as well as other non- injected warts.

The main advantage of PPD is that it is very cheap and freely available in India and is easy to administer. ${ }^{13}$ Common side effects after administration of PPD include pain, pruritis and discomfort at injection site. Development of ulcer or necrosis may rarely occur at the site of injection. There are various therapeutic modalities for the treatment of warts including electrocautery, cryocautery and chemical cautery. Since all these are destructive therapies, there are increased chances of scarring and pigmentary changes with these methods. Also, since the warts are known to clear spontaneously after the development of cell mediated immunity, so immunotherapy is beneficial and it is modality of choice as there are less chances of recurrence of warts and it is less destructive. ${ }^{14}$

\section{Conclusion}

The main limitation in our study was the absence of control group. Also, the sample size was small. More trials with larger number of patients need to be undertaken to prove the efficacy of PPD for the treatment of warts. 


\section{References}

1. Johnson SM, Horn TD. Intralesional immunotherapy for warts using a combination of skin test antigens: $A$ safe and effective therapy. J Drugs Dermatol 2004; 3: 263-5.

2. Sterling JC, Handfield-Jones $S$, Hudson PM. British Association of Dermatologists. Guidelines for the management of cutaneous warts. Br J Dermatol 2001; 144: 4-11. https:// doi.org/10.1046/j.1365-2133.2001.04066.x

3. Gibbs S, Harvey I, Sterling JC, Stark R. Local treatments for cutaneous warts. Cochrane Database Syst Rev 2006; 3: CD001781.

4. Horn TD, Johnson SM, Helm RM, Roberson PK. Intralesional immunotherapy of warts with mumps, Candida, and Trichophyton skin test antigens: A single-blinded, randomized, and controlled trial. Arch Dermatol 2005; 141: 589-94. https://doi.org/10.1001/ archderm.141.5.589

5. Johnson SM, Roberson PK, Horn TD. Intralesional injection of mumps or Candida skin test antigens: A novel immunotherapy for warts. Arch Dermatol 2001; 137: 451-5.

6. Dimoliatis ID, Liaskos CA. Six Mantoux tuberculin skin tests with $1,2,5,10,20$, and 50 units in a healthy male without side-effects - Is skin reaction a linear function of tuberculin dose? Cases J 2008; 1: 115. https://doi. org/10.1186/1757-1626-1-115

7. Froeschle JE, Ruben $\mathrm{FL}$, Bloh AM. Immediate hypersensitivity reactions after use of tuberculin skin testing. Clin Infect Dis 2002;34:12-3. https://doi.org/10.1086/324587

8. Eassa BI, Abou-Bakr AA, El-Khalawany MA. Intradermal injection of PPD as a novel approach of immunotherapy in anogenital warts in pregnant women. Dermatol Ther 2011; 24: 137-43. https://doi.org/10.1111/j.15298019.2010.01388.x

9. Ibraheem MA, Ahmed RE, Al Sadar $M$. Intradermal vs intralesional purified protein derivatives in treatment of warts. Gulf J dermatol 2011;1;18.

10. Wananukul S, Chatproedprai S, Kittiratsacha P. Intralesional immunotherapy using tuberculin PPD in the treatment of palmoplantar and periungual warts. Asian Biomedicin 2009; 6: 739-743.

11. Chandrashekar L. Intralesional immunotherapy for the management of warts. Indian Dermatol Venereol Leprol 2011; 77: 261-3. https://doi. org/10.4103/0378-6323.79694

12. Bacelieri R, Johnson SM. Cutaneous warts: An evidence-based approach to therapy. Am Fam Physician 2005; 72: 647-52.

13. Elela IM, Elshahid AR, Mosbeh AS. Intradermal vs intralesional purified protein derivatives in treatment of warts. Golf J Deramatol Venereol 2011; 18: 21-6.

14. Kus S, Ergun T, Gun D, Akin O. Intralesional tuberculin for treatment of refractory warts. J Eur Acad Dermatol Venereol 2005; 19: 515-6. https://doi.org/10.1111/j.14683083.2004.01176.x 